\title{
A concorrência do mercado como elemento de afetação da gestão democrática nas cooperativas de crédito brasileiras
}

La competencia del mercado como elemento de afectación de la gestión democrática en las cooperativas de crédito brasileñas

\author{
Felipe da Silva Silveira \\ Aluno do Instituto de Ensino e Pesquisa Valor Humano - Univali, \\ de Santa Catarina, Brasil
}

Sumario: 1. Introdução. 2. O mercado de crédito. 3. A sociedade cooperativa diante do mercado de crédito. 4. Conclusão. Referências

Resumo: O princípio cooperativo da gestão democrática, enunciado pela Aliança Cooperativa Internacional, estabelece que os membros participam ativamente do desenvolvimento das cooperativas, atuando diretamente na formulação de suas políticas e nos processos de tomada de decisão. No entanto, acontece que esta previsão encontra um fio de fraqueza no sistema de crédito cooperativo brasileiro. Levando em consideração sua preocupação com a sobrevivência em um mercado em que compete com os bancos, as cooperativas de crédito no Brasil priorizam a assunção do perfil econômico e do comportamento mercadológico, ferindo a essência identitária do seu caráter cooperativo. Nesse sentido, o presente estudo tem o propósito de identificar o momento em que a competição substitui a ideia emblemática de um homem por um voto por um manto de formalidades e protocolos que causa a morte da participação ativa e direta dos membros na gestão da sociedade cooperativa. O objetivo é corrigir o curso de ação interno, protegendo assim a identidade do cooperativismo no sistema de crédito cooperativo no Brasil. O desenvolvimento do trabalho terá como base o método dedutivo da abordagem e utilizará pesquisas diretas.

Palavras-chave. Cooperativismo. Gestão Democrática. Concorrência. Identidade Cooperativa.

Resumen: El principio cooperativo de gestión democrática, enunciado por la Alianza Cooperativa Internacional, establece que los miembros participan activamente en el desarrollo de las cooperativas, actuando directamente en la formulación de sus políticas y en los procesos de toma de decisiones. Ocurre, sin embargo, que esta previsión encuentra un hilo de debilidad en el seno del 
sistema de crédito cooperativo brasileño. Teniendo en cuenta su preocupación por la supervivencia en un mercado en que compite con los bancos, las cooperativas de crédito en Brasil priorizan la asunción del perfil economicista y del comportamiento mercadológico, hiriendo la esencia identitária de su carácter cooperativo. En este sentido, el presente estudio tiene el propósito de identificar el momento en que la competencia sustituye la idea emblemática de un hombre un voto por un manto de formalidad y protocolos que provoca el fallecimiento de la participación activa y directa de los miembros en la gestión de la sociedad cooperativa. Se quiere, con ello, corregir la ruta de acción interna, resguardando-se la identidad del Cooperativismo en el sistema de crédito cooperativo en Brasil. El desarrollo del trabajo tendrá como base el método deductivo de abordaje, y hará uso de la investigación directa.

Palabras clave. Cooperativismo. Gestión Democratica. Competencia. Identidad Cooperativa.

Abstract: The cooperative principle of democratic management enunciated by the International Cooperative Alliance sets out that members participate actively in the development of cooperatives, acting directly in the formulation of their policies and decision-making processes. However, it turns out that this outlook shows certain weakness in the Brazilian cooperative credit system. Taking into account their concern for survival in a market where they compete with banks, credit cooperatives in Brazil prioritise the assumption of the economic-focused profile and market-driven behaviour, thus damaging the identity essence of their cooperative nature. In this regard, this study aims to identify the moment in which competition substitutes the flagship idea of one man, one vote for a layer of formality and protocols that causes the death of members' active and direct participation in the management of a cooperative society. The aim is, therefore, to redirect the internal action pathway, safeguarding the identity of Cooperativism in Brazil's cooperative credit system. This paper is based on a deductive approach and direct research.

Keywords: Cooperativism. Democratic Management. Competition. Cooperative Identity 


\section{Introdução}

Contemporaneamente, o Cooperativismo pode ser considerado como um dos maiores movimentos socioeconômicos do mundo, e talvez, depois do Evangelho, não haja outra história mais repetida em todas as línguas, do que a história dos Pioneiros de Rochdale: precursores da constituição formal da primeira sociedade cooperativa da história, na data de 21 de dezembro de 1844, na Inglaterra, durante a revolução industrial (GIDE, 1974).

No momento em que surge a Cooperativa de Rochdale, conforma-se o nascimento do modelo cooperativo —endossado mais tarde pela $\mathrm{ACl}$ (Aliança Cooperativa Internacional) - que até hoje vige, de norte a sul, e de leste a oeste e em toda e qualquer esfera social, econômica, racial e cultural do mundo. Formada por um grupo de 28 operários, em sua maioria tecelões que encontraram na cooperatividade uma alternativa para enfrentarem os dissabores da Revolução Industrial, os Probos de Rochdale reuniram seus esforços comuns sob a dinâmica de um sistema de autoajuda, autorresponsabilidade, democracia, igualdade, equidade, solidariedade, honestidade, transparência, responsabilidade e vocação social. Criaram, assim, seu próprio armazém, inaugurado com uma quantidade muito pequena de alimentos, mas suficiente para modificar a realidade precária de seu entorno. Dez anos mais tarde o movimento cooperativo britânico conhecera o surgimento de aproximadamente1000 cooperativas (HOLYOAKE, 1944; GIDE, 1974; BOOK, 1992; MIRANDA, 2012).

No Brasil, o surgimento do Cooperativismo data de 1889, pela criação da Sociedade Cooperativa Econômica dos Funcionários Públicos de Ouro Preto, em Minas Gerais, uma cooperativa de consumo que logo expandiu-se para Pernambuco, Rio de Janeiro, São Paulo e Rio Grande do Sul. Já o Cooperativismo de crédito nasce depois, em 1902, com a operante Cooperativa Sicredi Pioneira, de Nova Petrópolis, no Rio do Grande do Sul. Atualmente, o Brasil conta com cerca de 1100 cooperativas de crédito, 38 centrais cooperativas estaduais e 4 confederações cooperativas, congregadas entre os sistemas Sicoob, Sicredi, Unicred, Cecred e, Confesol, movimentando praticamente $6 \%$ da economia Nacional. (CAMPOS, 2003; OCB, 2012; MEINEN, PORT, 2014, PORTAL DO COOPERATIVISMO, 2017).

Verifica-se, assim, que o Cooperativismo de crédito na economia do Brasil é crescente, significativo e administra quantias consideráveis. Portanto, reger uma empresa deste tamanho sem ferir os seus princípios e valores axiológicos é tarefa complexa, exigindo dos seus administradores e membros sã consciência e técnica coopera- 
tiva para tal, especialmente no que tange a democracia entre os seus membros.

Desta maneira o presente estudo tem o propósito de identificar o momento em que a concorrência substitui a ideia emblemática de um homem um voto por um manto de formalidades e protocolos que provoca a morte da participação ativa e direta dos membros na gestão da sociedade cooperativa, buscando, para tal, compreender o mercado de crédito no Brasil, a sociedade cooperativa como agente no mercado de crédito, a raiz da identidade do Cooperativismo, as particularidades e diferenças entre banco e cooperativa de crédito e os prejuízos axiológicos percebidos entre mitos e ritos, postura de mercado das cooperativas de crédito, regulação das cooperativas de crédito, se entre o mercado financeiro e a gestão estratégica o lucro é a finalidade e, se a máxima um homem um voto é levada a cabo nas cooperativas de crédito brasileiras, para então verificar onde e de que maneira a concorrência mercadológica impacta na democracia cooperativa.

Isso porque o que costumeiramente se vê por parte dos conselhos de administração das cooperativas de crédito é a busca por gestores/diretores com capacidade intelectual voltada essencialmente para o mercado financeiro bancário e econômico, deixando-se de lado o saber cooperativo, para que existe, como se forma e como deve ser gerida uma cooperativa de crédito para que atinja o objetivo para o qual foi criada.

Aqui reside a relevância do presente estudo, pois o que se percebe nas cooperativas de crédito brasileiras é a evidenciação da concorrência e da postura de mercado negocial em detrimento das premissas que regem o Cooperativismo, afastando-se da genuína ideologia evoluída desde os estatutos de Rochdale. Gestores levantam bandeiras em nome do interesse coletivo quando, na prática, este sequer é ouvido, até porque é instado ao modelo de crédito cooperativo tão somente pelo preço e/ou diferenciais mercadológicos - como a suposta garantida distribuição de sobras-, e não pelo potencial associativo em busca de um interesse comum.

Por isso, o presente artigo aponta para a necessária correção de rota onde a ação da cooperativa se baseie na efetiva vontade dos sócios, exercida através da gestão democrática, em substituição ao tradicional clichê da concorrência, instigando assim o (re)conhecimento da axiologia rochdaleana no agir social e democrático da cooperativa. Afinal, o cooperado é parte desta entidade que garante dignidade humana não apenas aos seus membros, mas também à comunidade em que estes estão inseridos. 


\section{O mercado de crédito}

A intervenção do Estado no âmbito da economia, se ajusta em razão da influência de concepções políticas e filosóficas que legitimam o exercício da autonomia privada no âmbito financeiro. Portanto, a noção de mercado, nesse contexto, compreende uma intuição ideológica, pela qual a liberdade do indivíduo racional é exercida com a finalidade de maximizar suas utilidades. Esta ideia, tanto se mostra como verdade, que grande parte das atividades de produção dependem do crédito, servindo como instrumento fomentador do progresso e da expansão do setor comercial e industrial da economia (MIRAGEM, 2013; RIZZARDO, 2013).

Por assim dizer, o desenvolvimento do setor bancário fez com que a noção econômica de valor e a própria noção de moeda passassem a depender, em grande medida, dos padrões resultantes da atividade bancária e financeira, mediante a escrituração contábil de moeda e sua correspondência em relação aos registros de todas as instituições financeiras, regulados e supervisionados pelo CMN (Conselho Monetário Nacional) e BCB (Banco Central do Brasil) respectivamente (MIRAGEM, 2013).

Sendo assim, em operação bancária básica, a instituição financeira recebe o depósito à vista e empresta no mercado a prazo, crendo na razão de que, em regra, estes superavitários não retirem o seu dinheiro, mas se valham dele por meio de ordem de pagamento, pois estes confiam que o seu capital pecuniário permanecerá lá. Vê-se, então, que a confiança é a base do exercício da atividade financeira (WAISBERG \& GORNATI, 2012).

Como estes recursos transitam por meio de sucessivos depósitos entre instituições financeiras do próprio sistema financeiro, criam-se sucessivos ciclos de criação de moeda. Isso indicará, dentre as principais funções da regulação bancária e do seu ente regulador, a identificação e prevenção do denominado risco sistêmico, que se caracteriza pela incapacidade de uma ou mais instituições financeiras em cumprirem suas obrigações com seus clientes e/ou outras instituições, dando causa a uma crise generalizada de confiança que pode ser capaz de provocar reação em cadeia e se propagar por todo o sistema financeiro nacional (MIRAGEM, 2013).

O crédito e seu respectivo acesso, compreendem meio de aprimoramento das condições de existência de determinado entorno, e neste sentido, nas palavras do ex-presidente do BCB (Banco Central do Brasil) Alexandre Tombini:

Elevar a qualidade de vida da população mais pobre, de maneira que se reduzam as desigualdades sociais, é mais um passo no longo 
caminho a seguir para aprimoramento de inclusão financeira neste país e, consequentemente, para mitigação das desigualdades. Trilhar esse caminho é possível, e essa responsabilidade está no rol de nossas atribuições, na qualidade de agentes promotores do desenvolvimento (FELTRIM; VENTURA; DODL, 2009).

Como se vê, o crédito é instrumento que nasce da vontade e do anseio social, necessitando, porém, da intervenção comprometida do Estado para que haja a concretude do seu compromisso com o povo ao promover a inclusão financeira do indivíduo comum e ao zelar pela solidez e honradez das instituições financeiras que integram o Sistema Financeiro Nacional brasileiro.

\section{A sociedade cooperativa diante do mercado de crédito}

As cooperativas de crédito no Brasil, são instituições financeiras constituídas sob a forma de sociedade cooperativa, que tem por finalidade a prestação de serviços financeiros aos seus associados, como concessão de crédito, captação de depósitos à vista e a prazo, cheques, prestação de serviços de cobrança, de custódia, de recebimentos e pagamentos por conta de terceiros sob convênio com instituições financeiras públicas e privadas e de correspondente no País, além de outras operações específicas e atribuições estabelecidas na legislação em vigor (PINHEIRO, 2008).

As sociedades cooperativas de crédito se encontram em plena evolução, aumentando a sua atuação no mercado financeiro, e consagrando-se como entidade que confere apoio efetivo meio de desenvolvimento da sociedade, promovendo uma economia solidária baseada na autoajuda, a qual fortalece os vínculos sociais e promove a universalização do acesso ao crédito (SOUZA, 2017).

[...] a exemplo do que também ocorre em outros países, as cooperativas financeiras brasileiras apresentaram crescimento em 2016 mesmo em um cenário de retração econômica e crise política. Os depósitos administrados pelas cerca de 1.000 instituições financeiras cooperativas existentes no país (somadas ainda as centrais e os bancos cooperativos) cresceram $26 \%$ e as operações de crédito $9 \%$ (PORTAL DO COOPERATIVISMO FINANCEIRO, 2017).

[...] observadas isoladamente, as principais cooperativas paranaenses são gigantes. Quinze delas têm faturamento superior a $R \$ 1$ biIhão. Em sete anos, contados até 2015, esse "grupo das bilionárias» ganhou nove integrantes. Eram apenas seis em 2008. Vistas em um só bloco, então, elas representam uma potência. Juntas, têm receita 
bruta de $R \$ 60,4$ bilhões (as dez maiores detêm $61 \%$ desse total). Uma estimativa da Organização das Cooperativas do Paraná (Ocepar) indica que esse faturamento conjunto pode atingir $R \$ 100$ bilhões em 2020 (PORTAL DO COOPERATIVISMO FINANCEIRO, 2017).

[...] cooperativas de crédito querem conquistar Brasil. Crescimento de dois dígitos? [...] as grandes cooperativas do sul do país avançam a taxas superiores a $20 \%$ ao ano. (REVISTA ÉPOCA NEGÓCIOS - GLOBO, 2017).

Outrossim, as cooperativas de crédito brasileiras migraram de uma participação nos ativos totais de 0,20\%, em 1995, para 2,53\% em 2013, apresentando um crescimento de $14.049 \%$ em 18 anos, enquanto que o SFN como um todo cresceu $998 \%$ no mesmo período. Considerando a década 2003 a 2013, apenas, a média de crescimento do sistema financeiro foi de $17,3 \%$ ao ano, ao passo que as cooperativas de crédito tiveram sua média em $24,5 \%$ ao ano (MEINEN; PORT, 2014).

Nesta fase de crescimento, especialmente a partir de 2009, as cooperativas de crédito no Brasil se apresentaram para além da atividade básica da intermediação financeira, passando a também ofertar produtos e serviços até então disponíveis no portfólio dos bancos (MEINEN \& PORT, 2014). Por outro lado, há a sensação de que este crescimento mercadológico reduziu a percepção dos associados sobre o verdadeiro objetivo de uma instituição financeira cooperativa.

\subsection{Para começo de conversa: o conceito de cooperativa e a raiz da identidade do Cooperativismo}

Desde a época em que se tem notícia dos homens mais antigos, a convivência humana é pautada em grupos rudimentares que praticam a cooperação como forma de ajuda mútua. Desde as primeiras manifestações espontâneas de cooperação nas comunidades mais primitivas até a constituição, em 1844, da cooperativa dos justos Pioneiros de Rochdale - que marca o início do Cooperativismo moderno-, se conta com uma larga experiência prática e um importante caudal teórico e metodológico acumulado, que dá suporte ao homem cooperativo (MIRANDA, 2012; ALBERT, 2011).

Divar (2012) comenta que as doutrinas econômicos-sociais que sucederam o Cooperativismo e que tem como base recíproca o associacionismo (Plockboy y Bellers), tiveram distintos caminhos, quais sejam, um enquanto desvio de rota radical e estatalista e outro como propulsor dos pensadores utópicos (Owen, Fourier e King), regulamentados 
a partir dos estatutos de Rochdale (1844) e com gênese de empresarialidade a partir da doutrina alemã da segunda metade do século XIX (Schulze, Raiffeisen e Haas), constituindo-se como movimento global a partir da fundação da ACl, em 1895.

Há que se destacar a importância da grandeza dos Pioneiros de Rochdale para o movimento cooperativo global moderno, e neste rumo, de grande sabedoria são as palavras do professor Charles Gide (1974):

Hay cooperativas de consumidores que solo buscan los precios económicos y la venta a precios de costo. Se equivocan. !Que miren a los Pioneros de Rochdale!

Otras y - y muy numerosas, sobre todo en Inglaterra- que solo ven en la cooperación el consumo y olvidan al productor. ! Que miren a Rochdale! Los Pioneros no habían olvidado que la cooperación está hecha para el productor tanto para el consumidor y no los había separado em la ciudad común que preparaban.

Y las hay, en fin - sobre todo em Francia- que no se ocupan para nada de la instrucción de sus miembros. !Que miren a los Pioneros de Rochdale! Estos habían introducido en los artículos de su constitución una reserva del dos y medio por ciento de los excedentes para aplicar a su instrucción y a la de sus camaradas. Sabían por instinto, y os lo enseñan, que este era el único modo de impedir que la cooperación degenerara en «negocio».

Pioneros, si tomo la palabra en nombre de las delegaciones extranjeras, nos es solamente para agradeceros vuestra cordial hospitalidad, sino para expresar los sentimientos que inspira en el corazón de todo cooperador el nombre glorioso de los Pioneros de Rochdale.

Ainda, na linha do tempo, a ACl faz jus a importante papel na história do Cooperativismo mundial, promulgando a atual definição do conceito de cooperativa, vejamos:

La cooperativa es una asociación autónoma de personas que se agrupan voluntariamente para satisfacer sus necesidades y aspiraciones comunes de carácter económico, social y cultural mediante una empresa de propiedad conjunta y gestionada democraticamente.

Cooperar, é, portanto, antes de tudo, fomentar o progresso e o bem-estar da humanidade. A sociedade cooperativa neste sentido assume um duplo aspecto, sendo: o econômico, que figura como estrutura organizada para o mercado; e o social, ideológico, que se apresenta como uma associação de pessoas que se aproximam por interesses comuns, buscando a satisfação socioeconômica e a transformação moral do indivíduo (MIRANDA, 2012). 


\subsection{Cooperativa de crédito e Instituições bancárias: entre mitos, ritos e prejuízos axiológicos}

Independentemente do tipo de mercado que atua, e do ramo sob qual se configura, observa-se que no ambiente cooperativo existe uma máxima de «tener espíritu cooperativo, es adherir y aprobar en profundidad y en forma motivada a la moral cooperativa y a los objetivos propuestos por las cooperativas» (LASSERRE, 2008).

Com base neste ideal, faz-se importante destacar as particularidades e diferenças entre banco e cooperativa de crédito especificamente. Mesmo que classificadas pela Constituição Federal de 1988 em seu artigo 192 (BRASIL, 1988) como instituições financeiras, ainda que submetidas às regras do CMN, assim como os bancos, e apesar de possuírem em comum o nome de alguns produtos e serviços que prestam, as cooperativas de crédito possuem características particulares que as diferem das outras instituições financeiras (MEINEN; SOUZA, 2010).

As cooperativas de crédito são administradas democraticamente mediante o esforço comum de seus membros, e em sistema de autoajuda, que objetiva a satisfação da coletividade, proporcionando-lhes crédito em moeda por meio da mutualidade e da economia comum entre estes, aplicando-se - em tese - taxas de juros e custos operacionais abaixo daqueles praticados pelos bancos comerciais em forma de Sociedades Anônimas. E tudo isso, exatamente, porque o objetivo social da cooperativa de crédito tem como norte o respeito aos princípios cooperativos e a distribuição dos dividendos de forma proporcional às atividades realizadas pelo cooperado, conforme definido em AGO (Assembleia Geral Ordinária), realizada anualmente para definir as diretrizes de cada exercício (MEINEN; SOUZA, 2010).

Reforçando este argumento de diferenciação entre os bancos e as cooperativas de crédito, eis o relato do Ministro Domingos Franciulli Netto (Superior Tribunal de Justiça) e do Ministro Gilmar Mendes (Superior Tribunal Federal), respectivamente (MEINEN; PORT, 2012):

[...] no interior, os gatos têm o costume de dormir junto às brasas do forno dos fogões de lenha, mas pela manhã, ao saírem desses fornos dos quais, geralmente, saem pães, não deixam de ser gatos. Pão é pão, gato é gato. E cooperativa é cooperativa e banco é banco.

[...] estão dizendo que pardal e canguru são a mesma coisa porque saltam. 
Neste sentido, a Lei de Cooperativismo n. ${ }^{\circ}$ 5.764/71 em seu artigo 5. ${ }^{\circ}$, parágrafo único, traz que: «é vedado às cooperativas o uso da expressão Banco» (BRASIL, 1971).

Todas essas distinções podem ser melhor compreendidas ao se responder a seguinte pergunta: quais são, respectivamente, as origens e os objetivos de uma cooperativa de crédito e os de uma instituição financeira tradicional? A cooperativa nasce da vontade e da necessidade de um grupo de pessoas, que se congregam democraticamente para o exercício da mutualidade em busca de soluções. Já as instituições financeiras mercantis surgem da convicção unilateral do dono do capital, sem qualquer consulta ao usuário, com o único objetivo de ampliar (rentabilizar) o capital investido (MEINEN; PORT, 2012).

Malgrado o estágio de evolução tecnológica que a humanidade enfrenta no ápice de seu ingresso no século XXI, sua característica egolatria todavia subsiste, de modo que, ainda, «para el humano, el bien general solo parece ser bien en cuanto posible, comprensible, por extensión, se su propio bien». Este traço egocêntrico, por demais distante do espírito da cooperatividade, acaba de uma ou de outra forma contaminando as cooperativas de crédito, como reflexo do modus operandi dos gestores que pautam sua atuação no mercado negocial (DIVAR, 1985; MIRANDA, 2012).

A realidade tem demonstrado que no afã de buscar o caráter concorrencial, as cooperativas têm recorrido a contratação de agentes diretivos com experiência administrativa extra cooperativa, e que pelo desapreço a ideologia e aos princípios cooperativos, ao se tornarem os mestres da entidade, desenvolvem atitudes arbitrárias, as vezes até mesmo mais abomináveis que as dos piores dirigentes de empresas capitalistas, deteriorando seu caráter, já que a base democrática e a vocação social são esquecidas em favor da adaptação as exigências do mercado (MIRANDA, 2012).

Portanto, mesmo normatizadas dentro do ambiente do sistema financeiro nacional as cooperativas de crédito devem preservar sua identidade, e compreender que «la solución cooperativa sólo alcanzará su plena medida si una cantidad suficiente de hombres del sector cooperativo alcanza la calidad humana necessária (LASSERRE, 2008).

Como se percebe, a perda da identidade cooperativa e a sua desvirtuação ideológica resulta do anseio pela capacidade de adaptação as concorrências emanadas do mercado e a consequente transformação do membro cooperativo em um ser anônimo, entristecido, insatisfeito. Nos anos oitenta o auge da falta do espírito de sociedade cooperativa se deu pelas distorcidas práticas de mercado, os princípios permaneceram apenas no papel, os valores foram abandonados e o que se nota 
é uma tendência autodestrutiva que contaminou em grande parte cooperativas de distintos países em desenvolvimento (MIRANDA, 2012).

\subsection{Cooperativa de crédito e postura de mercado: Banco Cooperativo ou Cooperativa banco?}

As cooperativas de crédito em espécie, possuem DNA, legislação e regulação suficientes que lhes permite atuar em consonância com os preceitos cooperativos.

No campo mercadológico, mesmo pensadores clássicos do capitalismo como Porter (0000) compreendem que a eficácia operacional não é estratégia, afinal, o posicionamento de mercado é algo cada vez mais volátil, notadamente, no mercado financeiro comum —os bancos-, e embora o modelo cooperativo seja único diante de sua raiz axiológica e social, a concorrência com modelos empresariais de natureza capitalista pode provocar a insustentabilidade das cooperativas.

Se a cooperativa competir com o banco no quesito da eficácia operacional, presente-se que sua visão social não conseguirá sobreviver por si só frente ao setor mercantil predador, afinal, cooperativa faz menos marketing do que o banco, tem menos spread do que o banco, tem índice de eficiência econômico mais caro do que o banco, tem menos capacidade de investimento do que banco. Consequência disso é que uma atuação pautada na concorrência com um modelo diverso pode ser sustentável a curto prazo, mas destrutivo a longo, justamente porque essa competição consumirá, aos poucos, sua matriz identitária (MICHEL; PORTER, 0000; MIRANDA, 2012).

Em contrapartida, atuando de maneira não combatente com a eficácia operacional e sim, estrategicamente, valendo-se do manto que guarnece as cláusulas pétreas do Cooperativismo, como a autoajuda, a autorresponsabilidade, a democracia, a igualdade, a solidariedade, a honestidade, a transparência, a responsabilidade e a vocação social, que representam os pilares do modelo ideal de atuação da empresa cooperativa, é que estas podem prosperar sem se expor ao risco do embate auto dilapidador da competição e de expor o manto genético do Cooperativismo a discursos esvaziados de prática cooperativa. Assim, tendo a possibilidade livre e desimpedida de caminhar por uma rota alternativa nas comunidades onde atua, que lhe é intrínseca e inerente a sua razão de existir: o caminho da dignidade e evolução da pessoa humana.

Tendo, o modelo empresarial cooperativo, uma rota alternativa, justa, digna e eficaz, caminhar pela rota concorrencial com os bancos 
é auto castigar-se, e sobre a finalidade do castigo, Nietzsche (1882) bem dizia: "O castigo tem por finalidade tornar melhor aquele que castiga - aí está o último recurso para os defensores do castigo». E por assim dizer, Miranda (2012) traz cirúrgica mensagem sobre a concorrência das cooperativas com o mercado:

Aún que intenciones honorables se muestren como la cuna de una educación fortalecida por principios sublimes que aguanten virtudes diversificadas, es sabido por todos que la codicia, la envidia, el egoísmo y el deseo de poder y de poseer son peculiaridades propias de la naturaleza humana. Al observar que el apetito por el domino y por el beneficio personal acompaña el hombre desde que ha dado su primer paso por la tierra, Divar anota que «para el humano, el bien general solo parece ser bien en cuanto posible, comprensible, por extensión, de su propio bien. Esta lección, de indeleble sabiduría, refleja el modus operandi del comportamiento de los gestores de las entidades jurídicas que buscan ocupar y mantener un espacio en el mercado negocial.

Como se vê, a competição baseada apenas na eficácia profissional é mutuamente destrutiva, levando a guerras de desgaste que terminam apenas com a limitação da competição, e neste rumo, a verve da mensagem de (MICHEL \& PORTER, 0000) é pontual:

O constante aprimoramento da eficácia operacional é imprescindível para a consecução da rentabilidade superior. No entanto, em geral, não é o bastante. Com base apenas na eficácia operacional, poucas empresas competem com êxito durante períodos mais prolongados, enfrentando dificuldades cada vez maiores em manter-se a frente dos rivais. A causa mais óbvia desta situação é a rápida proliferação de práticas melhores. Os concorrentes conseguem imitar com rapidez as técnicas gerenciais, as novas tecnologias, as melhorias de insumos e as formas superiores de atender às necessidades dos clientes.

Visto isso, prevê-se, que depois de um lapso temporal de aproximadamente uma década de ganhos com grande lastro baseadas na eficácia operacional, muitas empresas passaram a se ver numa situação de retornos decrescentes, pois a melhoria contínua foi incutida no cérebro dos gestores, e, inadvertidamente, as ferramentas foram arrastando as empresas em direção a imitação e à homogeneidade. Gradualmente, os gestores permitiram que a eficácia operacional suplantasse a estratégia, e o resultado é uma competição de soma zero, com preços estáticos ou declinantes e pressões de custo que comprometem a capa- 
cidade das empresas de investir no negócio a longo prazo (MICHEL \& PORTER, 0000).

Pensando-se na relativização da eficácia operacional, mas olhando para o posicionamento de mercado como uma estratégia fundamental onde o Cooperativismo a possui de maneira exclusiva, Miranda (2012) faz importante relação ao trazer que:

Considerando que las cooperativas se desarrollan para servir a sus asociados, podemos decir que, en un primer plan, la gestión cooperativa es aquella que preocupa asegurar la importancia de la cooperación, y busca garantizar el alcance de sus resultados, a través de una conexión entre los asociados, a administración de la entidad y la comunidad en general, de manera que se pueda revelar su perfil democrático, la responsabilidad de los directores, los deberes de los miembros, el control interno, la conducción de los riesgos relacionados al desarrollo de la actividad, la solución de los conflictos de intereses, el impacto social y la necesidad de preservar la identidad cooperativa, todo ello con la finalidad de generarse a cooperativas sólidas, propias a la competencia del mercado, transparentes y confiables.

As empresas cooperativas não possuem o condão de salvar o mundo, mas ajudam a melhorá-lo, portanto, para que prosperem pelo viés da cooperação, é importante que as cooperativas se posicionem no mercado de maneira tal que não seja meramente pelo aspecto mercadológico das entidades comuns do sistema financeiro nacional, mas sim, com atuações pautadas nos valores e premissas que guarnecem o Cooperativismo nas relações entre cooperativa e cooperado, diferentemente das costumeiras praticadas entre banco e cliente (HENRY, 2013; MEINEN; PORT, 2014).

\subsection{Mercado financeiro e gestão estratégica: é o lucro a finalidade?}

Quando determinada empresa é autossustentável economicamente, deve produzir um resultado positivo, e isso não significa que o propósito da atividade é meramente um benefício capitalista através da obtenção de lucro em sentido estrito, logo, a questão não é a distinção entre "com fins de lucro» ou "sem fins de lucro», mas sim, da obtenção de um lucro em relação ao propósito da entidade. Ora, pois, a obtenção de lucro é o propósito máximo da atividade e um meio para melhorar a situação dos beneficiários da entidade para que alcancem seus mais amplos anseios sociais? (HENRY, 2013). 
O aspecto da «não geração de lucro» não está claro para numerosos cooperativistas, pois o confundem com a «não geração de riqueza» e com a inexistência de possibilidade de obtenção de "avanços que possibilitem a melhora da qualidade de vida do homo cooperativus». A ausência da intenção especulativa é um atributo exclusivo da cooperativa e de seus cooperados, eis que não se assemelha com a criação de riqueza e sua capitalização e nem com o lógico e natural desejo humano de alcançar melhores rendimentos e qualidade de vida (DELGADO, 2016).

Contudo, há que se dizer que produzir excedentes adequados é necessário para proporcionar melhor qualidade de vida aos seus cooperados, fomentar a base econômica para fortalecer os fundos que sustentam o futuro da cooperativa e do Cooperativismo, dotar-se de ferramentas que permitam crescer em uma economia de mercado normalmente adversa, deduzir de associados irresponsáveis os montantes que, por negligência ou irresponsabilidade, a cooperativa teria pago por eles, e de modo geral, promover o bem estar e a dignidade da pessoa humana no entorno cooperativo (DELGADO, 2016).

Nas palavras de Laire apud Delgado (2016):

A constituição de uma cooperativa procede assim da vontade dos seus fundadores de verem reduzir o preço de custo dos produtos, pela supressão dos intermediários no processo de produção. [...] o projecto cooperativo ultrapassa o estrito plano financeiro ou económico. A supressão do intermediário é também a supressão do lucro "capitalista» no sentido jurídico do termo, quer dizer o desaparecimento do custo da remuneração do capital. É também a vontade de se ver esbater ${ }^{1}$ as noções de patronato e de salariado, de subordinação e de hierarquia, em benefício de um ideal, defendendo no mundo do trabalho o esforço comum e o igualitarismo. O estatuto dos membros da cooperativa bem como o objetivo que ela persegue, ilustra bem essa doutrina.

Se vê, assim, pelo que fora dito, que admitir o lucro como fim nas cooperativas de crédito, é abrir caminhos à confusão, é pôr em causa a sua identidade e a sua razão maior de ser, com riscos de perturbar o desenvolvimento cooperativo de crédito de maneira gravosa (NAMORADO, 2000).

\footnotetext{
1 Atenuar; adoçar; tirar as asperezas. https://www.dicio.com.br/esbater/
} 
3.5. Assembleia Geral, um homem e um voto e o princípio da gestão democrática: quando a cooperativa de crédito fere a regra da cooperatividade?

Desde os pensadores utópicos do Cooperativismo (séculos XVII e XVIII), passando pelos Pioneiros de Rochdale (1844) e pelo conceito de identidade cooperativa dado pelo órgão máximo do Cooperativismo mundial, a $\mathrm{ACl}$, que a base da gestão da empresa cooperativa é guiada por meio dos valores e princípios cooperativos como pilares sustentadores da cooperação, dos quais o princípio da gestão democrática pelos seus membros representa a espinha dorsal do pensamento cooperativo. Os membros individuais são o coração do movimento e se espera que, direta ou indiretamente, participem em todas as atividades essenciais da cooperativa, e que a cooperativa participe da formação social, econômica e cultural da sociedade onde está inserida (BOOK, 1992; SOUZA, 2017).

A democracia é valor de cláusula pétrea nas cooperativas, é a democracia que provoca a ação consciente fundamental que difere o modelo societário cooperativo dos outros modelos empresariais existentes, privilegiando a participação democrática de todos os seus membros pelo simples fato de serem membros (SCHNEIDER, 1991, apud, SOUZA, 2017).

Segundo a $\mathrm{ACl}$ (2015), o 2. ${ }^{\circ}$ princípio do Cooperativismo mundial: a gestão democrática, é:

Las cooperativas son organizaciones democráticas bajo el control de sus miembros, los cuales participan activamente en la determinación de sus políticas y en la toma de decisiones. Los hombres y las mujeres que ejercen como representantes elegidos son responsables respecto a todos los miembros. En las cooperativas de primer grado los miembros tienen los mismos derechos de votación (un miembro, un voto) y las cooperativas de otros niveles también se organizan de manera democrática.

Posto isso, frente ao caráter coletivo da participação e da democracia, os membros da cooperativa devem participar no processo de desenvolvimento de modo com que transformem seus recursos individuais e sua própria vontade em mecanismos de ação coletiva que, para além da busca de seu próprio benefício, reflita realizações que promovam o contínuo processo de melhoria e aperfeiçoamento do bem-estar das pessoas que, com ele, compartilham espaço de vida no entorno social. (MIRANDA, 2012).

Na prática, a democracia é um conceito delicado e a governança democrática de qualquer instituição humana é uma tarefa complexa. 
Governar uma cooperativa de forma sábia e democrática não é, portanto, exceção, e fomentar o espírito democrático dentro das cooperativas é uma atividade interminável, difícil, porém, fundamental e valiosa do ponto de vista social $(\mathrm{ACl}, 2015)$, vejamos:

Para conseguir un mayor nivel de participación, algunas cooperativas utilizan incentivos de participación. Pueden ser sencillos, como dispensar refrescos en las reuniones, o más elaborados, como organizar sorteos u otras recompensas positivas para los miembros activos. Sin embargo, las cooperativas no deberían depender demasiado de los incentivos. Al aplicar el 5. ${ }^{\circ}$ principio da educación, formación e información, los miembros habrán sido concienciados e informados sobre sus derechos y responsabilidades en calidad de miembros para ejercer un control democrático en su cooperativa.

E ainda $(\mathrm{ACl}, 2015)$ :

Uno de los mayores retos a los que se enfrentan las cooperativas al poner en práctica el principio del control democrático por parte de los miembros es crear una cultura donde el debate sea bien recibido y fomentado en lugar de reprimido. El debate animado y controvertido debe tomarse como un signo de democracia saludable que se debe reflejarse en las partes más formales de la estructura democrática de una cooperativa, en particular, animando a los miembros a participar activamente en sus cooperativas y a presentarse como candidatos a las elecciones.

Como se nota —à luz do exercício da democracia-, o discurso necessita ser estimulado, e com isso, é importante que a democracia cooperativa aproveite as evoluções tecnológicas, através do advento da internet e do celular, por exemplo, de maneira com que mais facilmente se desenvolvam estratégias que impliquem no envolvimento ativo dos membros nos processos democráticos. Devendo, inclusive, mediante o devido processo democrático, deliberar sobre a revogação e a destituição de representantes que se aproveitem da sua posição e que não cumpram com rigor as funções de membro eleito $(\mathrm{ACl}$, 2015).

Para o fomento saudável e democrático da AGO (Assembleia Geral Ordinária) das cooperativas de crédito, a $\mathrm{ACl}$ destaca que as decisões estratégicas chave sobre políticas deverão ser explicadas com clareza, de maneira concisa e de forma com que todos os membros possam entender e possam oferecer opções alternativas quando o proceda $(\mathrm{ACl}$, 2015). 
Nesta toada, o próprio BCB já observou efeitos que em específicas regiões onde o Cooperativismo financeiro é mais desenvolvido, ocorre melhor participação dos membros da cooperativa nas tomadas de decisão, e este fato é associado ao aspecto positivo que representa nas decisões e no fortalecimento da cooperativa. Por esta razão, percebeu-se uma relação positiva entre o nível mais avançado do Cooperativismo de crédito como parte da economia local e a maior presença do associado no dia a dia da cooperativa (BCB, 2013/2014).

Aplicar com rigor o $2 .^{\circ}$ princípio do Cooperativismo, como já visto, é trabalhoso, necessário e valioso para que a ascensão da cooperativa de crédito ocorra pautada nos preceitos cooperativos axiológicos e a complexidade dos procedimentos democráticos e dos códigos de governança é determinado pela escala e desenvolvimento de cada cooperativa. Numa cooperativa nova e pequena e em uma economia emergente, necessitará de metodologia mais simplificada, já na cooperativa de grande envergadura necessitará de metodologia e manual de governança bastante detalhado. E sejam cooperativas pequenas ou grandes, implementar recursos essenciais de governança democrática e de boas práticas garantirá a soberania dos seus membros e seus direitos democráticos ( $\mathrm{ACl}, 2015)$.

De acordo com o $B C B$, no que tange à representatividade quantitativa nas Assembleias Gerais, as cooperativas de crédito persistem com baixa participação dos membros e há percepção de maior aderência e melhor qualidade na representação dos sócios na Assembleia quando em sistema de delegação (BCB, 2013/2014).

Num paralelo do exercício da democracia, sob a ótica das estratégias de ganho de robustez no mercado financeiro de crédito tal qual os bancos, a máxima: um membro, um voto; e o $2 .^{\circ}$ princípio do Cooperativismo: gestão democrática pelos membros; revelam-se nas Assembleias Gerais como um manto de formalidades e protocolos que não representam o anseio do ser humano que busca na cooperativa o meio para atingir o seu bem-estar e de seus semelhantes, mas sim, a falsa sensação de democracia ao conduzir um discurso de labiríntica compreensão de modo que a decisão dos rumos da cooperativa já vem de gabinete, quando deveria emanar da vontade dos sócios, com consciência promovida através do $5 .^{\circ}$ princípio do Cooperativismo.

Por fim, tem-se a sensação de que os princípios e valores cooperativos acabam sendo relativizados em detrimento das estratégias de concorrência que se valem os modelos societários estritamente mercantis, como os bancos, e a consequência disso é perda da identidade cooperativa, de maneira tal que o homo cooperativus ao levantar sua ban- 
deira de luz é comparado ao sujeito que é forçado a deixar a escuridão descrito por Platão no mito da caverna: um louco, insano, visionário, utópico.

\section{Conclusão}

Empiricamente o que se percebe é que as cooperativas de crédito brasileiras no afã de buscarem robustez no mercado. No afã de atender as exigências do CMN e do BCB e suas regulações comerciais, prudenciais e de garantia, - como as limitações impostas, por exemplo, pelo capítulo V da Resolução 4.434/2015 (CMN, 2015)—. No interesse de aumentar a base de cooperados. No afã de aumentar os ativos da instituição, sob o discurso generalizado de taxas de crédito menores e da remuneração das cotas-capital, acaba por se assemelhar em muito as empresas bancárias convencionais, pautando sua atuação pela concorrência, e não pela cooperação, comprometendo todo o arcabouço axiológico da entidade cooperativa de crédito.

Traçando-se um paralelo entre as alterações impostas pela Resolução 4.434/2015 do CMN e a Declaração de Identidade Cooperativa da $\mathrm{ACl}$, tem-se a impressão de que os governos tendem a continuar não compreendendo a verdadeira razão de ser das cooperativas de crédito de maneira plena enquanto empresa social, uma vez que a mens legis desta resolução se mostra sob o aspecto meramente econômico, de eficiência operacional, sob os mesmos preceitos regulatórios aplicados às demais entidades que integram o Sistema Financeiro Nacional. E por mais que se reconheça a necessidade de regramentos específicos de operações, limites de patrimônio e políticas de governança, este mesmo CMN deveria, à luz do artigo 192 da Constituição Federal do Brasil de 1988, desenvolver aspectos normativos que também dessem vigor a efetiva participação de seus membros e fomentasse as premissas identitárias do Cooperativismo pregadas pela $\mathrm{ACl}$ (SOUZA, 2017).

Pelas razões apontadas, se tem a impressão de que as cooperativas de crédito caminham pela rota da concorrência, com o modus operandi dos bancos, onde o discurso e o marketing são voltados para abertura de contas correntes e não para a associação consciente do cooperado, e onde o preço do crédito e retorno das sobras é o argumento que busca atingir a meta de concessão de crédito, não pela compreensão da necessidade daquele determinado grupo de pessoas que se unem para praticar a cooperação, mas para buscar se posicionar no mercado concorrencial de crédito. 
Causa desta concorrência e similitude com os bancos, é a vigente inadimplência experimentada pelas cooperativas de crédito no âmbito do SFN, é o aumento das demandas vindas de órgãos que visam proteger o consumidor frente as empresas capitalistas, como os PROCON'S (Programa de Proteção e Defesa do Consumidor), é o aumento significativo das demandas judiciais que evocam o CDC (Código de Defesa do Consumidor) nas relações entre a cooperativa e seus donos, é o arcabouço regulatório estatal pelo CMN cada vez mais voltado ao aspecto econômico e da eficácia operacional ao aproximar as regulações da cooperativa de crédito com a dos bancos: haja vista o recente aumento do IOF (Imposto Sobre Operações Financeiras), haja vista a iminência do aumento da PIS e COFINS, e é o falecimento gradual do princípio da gestão democrática entre os cooperados. (CONTABILIDADE E GESTÃO EMPRESARIAL, 2017; BCB, 2015; PORTAL DO COOPERATIVISMO, 2017; VALOR ECONÔMICO, 2017; G1, 2017).

O homo cooperativus, em razão, e diferentemente, dos desleais que corrompem o exercício das atividades negociais comuns, atua de maneira equilibrada, transparente e honesta (MIRANDA, 2012):

Considerando que el canal que aproxima la autogestión y la solidaridad del entorno donde se encuentra inserida, la cooperativa presenta la premisa de que la felicidad Humana es la esencia de la producción y de la circulación de bienes e servicios.

Con base en ello, se puede percibir que diferente de lo que ocurre con los socios de la sociedad empresaria-capitalista, los cooperados remiten el interés especulativo para planes posteriores, y buscan aproximar el quehacer cooperativo de las acciones volcadas al auxilio de cuestiones Humanas, sean las de aspecto social, económico, político o ambiental.

São por estas razões, preponderantemente, que este estudo visa compreender se realmente é o conjunto de cooperados que decide os rumos da cooperativa de crédito, ou, se eles simplesmente através de um manto de formalidades e protocolos endossam a decisão de um colegiado específico da entidade cooperativa. Desse modo, confirmando a informação do BCB de que as Assembleias Gerais, nas cooperativas de crédito, em regra, possuem baixa participação do seu quadro associativo (BCB, 2013/2014).

Acredita-se que fomentando o $5 .^{\circ}$ princípio do Cooperativismo (educação, formação e informação), os cooperados tenham boa consciência para autogerir a sua cooperativa de crédito, maximizando os efeitos do $2{ }^{\circ}$ princípio do Cooperativismo (gestão democrática entre 
os membros), e proporcionalmente, minimizando os impactos negativos e os prejuízos axiológicos a que estão expostas contemporaneamente, em busca da sua razão máxima de existir: a felicidade humana e o bem-estar social.

O modelo da entidade cooperativa sob a ótica dos probos de Rochdale é de grandeza tamanha que a fome, a desigualdade social, a corrupção e todos os sintomas que afetam a existência humana talvez pudessem deixar de existir, pois auto gerindo-se de maneira democrática e eliminando fronteiras geográficas através do exercício do princípio da intercooperação, onde o princípio da dignidade humana e senso de coletivo se sobrepõe à qualquer possibilidade de interesse individualizado que o administrador de cooperativa eventualmente possa ter, e ao passo que se esse contágio avança, a ideologia passar a ser legitimada, encontrando aí o caminho para a aplicabilidade da gestão democrática entre os membros.

Em razão disto, há aí uma rota alternativa para diminuir esta forma deturpada de aplicar o Cooperativismo de crédito em espécie, onde a concorrência prevalece e a eficiência mercadológica dos administradores da cooperativa ditam as regras do cooperar que contemporaneamente vige, ao passo que se se debruçar sobre os pilares norteadores do Cooperativismo, sistematizados a partir de 1844, na Revolução Industrial, em Rochdale, na Inglaterra, o indivíduo passaria a ser dono do seu próprio destino e dos seus sonhos.

Concluindo, pelo todo exposto, acredita-se que é nesta correção de rota interna que as cooperativas de crédito passarão a ser fidelizadas e vistas como cooperativas democráticas pelos seus donos e usuários, do contrário, se continuará plantando concorrência e colhendo clientes em solo que se semeia democracia e se colhe cooperado.

\section{Referências}

Albert, Consuelo Estrella Izquierdo.: Cooperativismo, Identidad Cooperativa, Globalización: desafios en el siglo XXI, Editorial Académica Española, 2011.

BACEN: Fortalecimento da Governança Cooperativa no Brasil, Departamento de Supervisão de Cooperativas e de Instituições Não Bancárias, Pesquisa Governança em Cooperativas, 2013/2014.

Böök, Sven Ake: Valores cooperativos para un mundo en cambio: informe para el Congreso de la ACl, ACl, Tokio, 1992.

BrasIL: Constituição Federal de 1988, promulgada em 5 de outubro de 1988. Disponível em <http://www.planalto.gov.br/ccivil_03/constituicao/constituicaocompilado.htm>. Acesso 29 ago 2017. 
Brasil, PresidênCIA da República, Lei $n .^{\circ}$ 5.764, de 16 de dezembro de 1971. Define a Política Nacional de Cooperativismo, institui o regime jurídico das sociedades cooperativas, e dá outras providências. Disponível em <http:// www.planalto.gov.br/ccivil_03/LEIS/L5764.htm>. Acesso 17 jul 2017.

CAMPos, Armando: Plexo normativo das cooperativas de crédito, OAB Editora, Brasília, 2003.

Conselho Monetário Nacional: Resolução CMN n. ${ }^{\circ} 4.434$, de 5 de agosto de 2015. Dispõe sobre a constituição, a autorização para funcionamento, o funcionamento, as alterações estatutárias e o cancelamento de autorização para funcionamento das cooperativas de crédito e dá outras providências. Disponível em <https://www.bcb.gov.br/pre/normativos/busca/normativo.as p?tipo=res\&ano=2015\&numero=4434> . Acesso 29 nov 2015.

CONTABILIDADE E GESTÃo EMPRESARIAL: Cooperativas de crédito estão mais restritivas com alta da inadimplência. Disponível em <http://www.ntwcontabilidade.com.br/noticias/cooperativas-de-credito-estao-mais-restritivas-com-alta-da-inadimplencia-dci/>. Acesso 10 set 2017.

Delgado, Oscar Bastidas: La Identidad Cooperativa, Intercoop, Editora Cooperativa Limitada, Argentina, 2016.

DIVAR, Javier Garteiz-Aurrecoa: La alternativa cooperativa: una respuesta ante la crisis, Ceac, Barcelona, 1985.

- Filosofía de la cooperación económica, Universidad de Deusto, Bilbao, 2012.

Feltrim, Luiz Edson; VenturA, Elvira Cruvinel Ferreira; DodL, Alessandra von Borowski: Projeto Inclusão Financeira - Pespectivas e Desafios Para Inclusão Financeira no Brasil: visão de diferentes atores, Banco Central do Brasil, Brasília, 2009.

GIDE, Charles: El Cooperativismo, Intercoop Editora Cooperativa Limitada, Buenos Aires, 1974.

G1: Cooperativas de Crédito querem conquistar o Brasil. Disponível em < http://epocanegocios.globo.com/Empresa/noticia/2017/01/cooperativas-decredito-querem-conquistar-brasil.html> Editora Globo S/A. Acesso 10 set 2017.

HenRŸ, Hagen: Orientaciones para la legislación cooperativa, OIT, Ginebra, 2013, 2. ${ }^{a}$ ed.

HolyOAKE, George, J.: Historia de los pioneros de Rochdale, Intercoop, Buenos Aires, 1975.

INTERNACIONAL CO-OPERATIVE AlLIANCE: Drafting of guindance notes: interpretation aids for the co-perative principles. Spanish version. Disponivel em: <http:/ / ica.coop/en/blueprint-themes/identity/guindancenotes>. Aceso em: 16 de out. 2015.

LASSERRE, Georges: El hombre cooperativo, EDUCC, Bogotá, 2008.

MeInen, Enio; SouzA, João Batista Loredo: Cooperativas de Crédito: Gestão Eficaz, Editora Confebrás, Brasília, 2010.

Meinen, Enio; Port, Márcio: O Cooperativismo de crédito ontem, hoje e amanhã, Confebrás, Brasília, 2012.

- Cooperativismo Financeiro: percurso histórico, perspectivas e desafíos, Confebrás, Brasília, 2014. 
Miragem, Bruno: Direito Bancário, Editora Revista dos Tribunais, São Paulo, 20113.

MIRANDA, José Eduardo de: De la crisis de identidad al rescate de la génesis del Cooperativismo, Dykinson S.L., Madrid, 2012.

NAMORADO, Rui: Introdução ao Direito Cooperativo: para uma expressão jurídica da cooperatividade, Almedina, Coimbra, 2000.

NietszCHE, Friedrich: A Gaia Ciência (tradução de Antônio Carlos Braga), Editora Escala, São Paulo, 2008.

PINHEIRO, Marcos Antonio Henriques: Cooperativas de crédito: história da evolução normativa no Brasil, BCB, Brasília, 2008, 6. ${ }^{\text {Ed. }}$

PORTAL do Cooperativismo: Cooperativismo Financeiro manteve crescimento em 2016. Disponível em < http://cooperativismodecredito.coop.br/>. Acesso 05 set, 2017.

- IOF e Instituições financeiras cooperativas: por que rever a decisão? Disponível em <http://cooperativismodecredito.coop.br/2017/04/iof-e-instituicoes-financeiras-cooperativas-por-que-rever-a-decisao-por-enio-meinen/>. Aceso 17 set 2017.

PORTER, Michael: Competição: estratégias competitivas, Elsevier, Rio de Janeiro, 1999.

Rizzardo, Arnando: Contratos de Crédito Bancário, Editora Revista dos Tribunais, São Paulo, 2013.

SCHNEIDER, José Odelso: Democracia, participação e autonomia cooperativa, Unisinos, São Leopoldo, 1991.

SouzA, Leonado Rafael de: A resolução CMN n. ${ }^{\circ} 4.434 / 2015$ e seu reflexo identitário-axiológico sobre as cooperativas de crédito, Unisinos, São Leopoldo, 2017.

VAlOR ECONÔMICO: Governo eleva IOF para cooperativas de crédito. <http:// www.valor.com.br/financas/4922746/governo-eleva-iof-para-cooperativasde-credito>. Acesso 17 set 2017.

WaIsBerg, Ivo; Gornatı, Gilberto: Direito Bancário: Contratos e Operações Bancárias, Editora Quartier Latin do Brasil, São Paulo. 